\title{
Retraction \\ Retracted: Influence of L-Tryptophan on Growth and Optical Properties of PbS Nanocrystalline Thin Films
}

\section{Journal of Nanomaterials}

Received 16 December 2020; Accepted 16 December 2020; Published 26 February 2021

Copyright ( 2021 Journal of Nanomaterials. This is an open access article distributed under the Creative Commons Attribution License, which permits unrestricted use, distribution, and reproduction in any medium, provided the original work is properly cited.

Journal of Nanomaterials has retracted the article titled "Influence of L-Tryptophan on Growth and Optical Properties of PbS Nanocrystalline Thin Films" [1]. As originally raised on PubPeer [2], the article was found to have concerns with some of the figures. A summary of the concerns is as follows:

(i) Figures 4(a), 4(c), and 4(e) (left-hand side) are identical to Figures 2(a), 2(b), and 2(c) in [3] despite [1] using tryptophan and [3] using lithium. A corrigendum has since been published to replace these figures in the other article [4].

(ii) Figure 4(a), 4(c), and 4(e) (right-hand side) are identical to Figures 1(a), 1(b), and 1(c) in [5], despite [1] using tryptophan and [5] using bismuth.

(iii) In Figure 14(a), the absorption spectra for PbS-T5 and PbS-T10 appear to be identical.

(iv) In Figure 3, the PbS-T30 and PbST20 traces appear to be identical. The PbS spectrum (black) also appears to be identical with the $\mathrm{PbS}$ spectrum in [6].

The journal and the editorial board are retracting the article due to concerns that the data in this article are not reliable. The authors do not agree to retraction.

\section{References}

[1] R. Palomino Merino, R. Gutiérrez Pérez, P. Trejo García et al., "Influence of L-Tryptophan on Growth and Optical Properties of PbS Nanocrystalline Thin Films," Journal of Nanomaterials, vol. 2018, Article ID 3431942, 15 pages, 2018.
[2] "Influence of L-Tryptophan on Growth and Optical Properties of PbS Nanocrystalline Thin Films," PubPeer, 2019, https:// pubpeer.com/publications/8D16E32378DE46D37140B5FC 5EA575.

[3] M. Chávez Portillo, J. Alvarado Pulido, S. Gallardo Hernández et al., "Voc enhancement of a solar cell with doped $\mathrm{Li}^{+}-\mathrm{PbS}$ as the active layer," Superlattices and Microstructures, vol. 118, pp. 137-144, 2018.

[4] M. Chávez Portillo, J. Alvarado Pulido, S. Gallardo Hernández et al., "Corrigendum to "Voc enhancement of a solar cell with doped $\mathrm{Li}+-\mathrm{PbS}$ as the active layer"," Superlattices and Microstructures, vol. 138, 2020.

[5] R. Gutiérrez Pérez, O. Portillo Moreno, L. Chaltel Lima, R. Palomino Merino, and M. Zamora Totozintle, "Optical and structural properties of PbS: $\mathrm{Bi}^{3+}$ nanocrystals," Revista Mexicana de Física, vol. 61, pp. 356-362, 2015, https:// scholar.google.com/scholar?hl=en\&as_sdt=0\%2C5\&q=optical + and +structural+properties +of +pbs $\% 3 \mathrm{~A}+\mathrm{bi} 3 \% 2 \mathrm{~B}$ + nanocrystals $+\& b \operatorname{btnG}=$.

[6] O. Portillo-Moreno, R. Gutierrez-Perez, M. Chavez Portillo et al., "Growth of doped PbS: $\mathrm{Co}^{2+}$ nanocrystals by Chemical Bath," Revista Mexicana de Fisica, vol. 62, pp. 456-460, 2016. 